\title{
Heterogeneous Catalysts for Petrochemical Synthesis and Oil Refining
}

\author{
Aleksandr Glotov ${ }^{1, *}$ iD and Eduard Karakhanov ${ }^{2, *}$ \\ 1 Department of Physical and Colloid Chemistry, Faculty of Chemical Technology and Ecology, \\ Gubkin Russian State University of Oil and Gas, 65 Leninsky Prosp., 119991 Moscow, Russia \\ 2 Department of Petroleum Chemistry and Organic Catalysis, Faculty of Chemistry, Lomonosov Moscow State \\ University, 1 Leninskie Gory, 119991 Moscow, Russia \\ * Correspondence: glotov.a@gubkin.ru (A.G.); kar@petrol.chem.msu.ru (E.K)
}

check for updates

Citation: Glotov, A.; Karakhanov, E. Heterogeneous Catalysts for Petrochemical Synthesis and Oil Refining. Catalysts 2021, 11, 602. https://doi.org/10.3390/ catal11050602

Received: 16 March 2021

Accepted: 19 April 2021

Published: 6 May 2021

Publisher's Note: MDPI stays neutral with regard to jurisdictional claims in published maps and institutional affiliations.

Copyright: (c) 2021 by the authors. Licensee MDPI, Basel, Switzerland. This article is an open access article distributed under the terms and conditions of the Creative Commons Attribution (CC BY) license (https:// creativecommons.org/licenses/by/ $4.0 /)$.
Keywords: petrochemical synthesis; oil refining; zeolites; aluminosilicates; organic and metal-organic frameworks; nanotubes; hydroprocessing; C-1 chemistry

In modern industry, more than $90 \%$ of processes are catalytic. Heterogeneous catalysis is among the major solutions for cost-effective and sustainable industrial applications and processing. Depending on the refinery and process, the development of heterogeneous catalysts is focused on the increase in feedstock conversion and selectivity to products. The design and development of highly efficient and stable heterogeneous catalysts represent an emerging frontier for overcoming energy and environmental challenges. Many industrial petrochemical and oil refining processes are facing new challenges that can be solved by using heterogeneous catalysts.

Recent trends in heterogeneous catalysis are: the design of new functional composite and nanostructured materials, including traditional zeolites' modification; the synthesis of nanoscale meso/micro materials; the investigation of dispersed nanosized systems; stabilizing and minimizing their aggregation; single-atom catalysis; new strategies for the development of predictable metal-support interaction, induced by a controlled synthesis of active phase and their dispersion. One of the modern routes is metal-organic and covalent frameworks' design with tunable textural and functional properties.

This Special Issue covers the most recent progress and advances in the field of heterogeneous catalysts based on mesoporous composites with embedded halloysite nanotubes covered with ruthenium nanoparticles for exhaustive benzene hydrogenation [1], in situ generated and supported on zeolites' transition metal sulfides for the hydrocracking of the pyrolysis fuel oil and n-alkanes isomerization [2,3]. This issue also includes investigations of novel rhodium systems supported on FeCrAl composite for the coupling of pre-reforming and partial oxidation to liquefied petroleum gas processing into syngas [4]. We have collected works devoted to the palladium catalysts based on porous aromatic frameworks and alumina for the hydrogenation of unsaturated compounds (alkynes, alkenes and dienes) and for the selective removal of acetylene from ethane-ethylene fractions $[5,6]$.

We hope that this Special Issue will be beneficial for researchers working in heterogeneous catalysis and functional materials design, such as zeolite composites, mesoporous materials, transition metal sulfides, aluminosilicates, porous aromatic frameworks, and metal nanoparticles immobilization.

Author Contributions: The contributions of A.G. and E.K. are equal. Both authors have read and agreed to the published version of the manuscript.

Funding: This research received no external funding. 
Data Availability Statement: The data that support the findings of this study are available in the literature cited.

Conflicts of Interest: The authors declare no conflict of interest.

\section{References}

1. Glotov, A.; Vutolkina, A.; Pimerzin, A.; Nedolivko, V.; Zasypalov, G.; Stytsenko, V.; Karakhanov, E.; Vinokurov, V. Ruthenium Catalysts Templated on Mesoporous MCM-41 Type Silica and Natural Clay Nanotubes for Hydrogenation of Benzene to Cyclohexane. Catalysts 2020, 10, 537. [CrossRef]

2. Kuchinskaya, T.; Kniazeva, M.; Samoilov, V.; Maximov, A. In Situ Generated Nanosized Sulfide Ni-W Catalysts Based on Zeolite for the Hydrocracking of the Pyrolysis Fuel Oil into the BTX Fraction. Catalysts 2020, 10, 1152. [CrossRef]

3. Pimerzin, A.; Savinov, A.; Vutolkina, A.; Makova, A.; Glotov, A.; Vinokurov, V.; Pimerzin, A. Transition Metal Sulfides- and Noble Metal-Based Catalysts for N-Hexadecane Hydroisomerization: A Study of Poisons Tolerance. Catalysts 2020, 10, 594. [CrossRef]

4. Potemkin, D.I.; Rogozhnikov, V.N.; Uskov, S.I.; Shilov, V.A.; Snytnikov, P.V.; Sobyanin, V.A. Coupling Pre-Reforming and Partial Oxidation for LPG Conversion to Syngas. Catalysts 2020, 10, 1095. [CrossRef]

5. Kulikov, L.; Kalinina, M.; Makeeva, D.; Maximov, A.; Kardasheva, Y.; Terenina, M.; Karakhanov, E. Palladium Catalysts Based on Porous Aromatic Frameworks, Modified with Ethanolamino-Groups, for Hydrogenation of Alkynes, Alkenes and Dienes. Catalysts 2020, 10, 1106. [CrossRef]

6. Melnikov, D.; Stytsenko, V.; Saveleva, E.; Kotelev, M.; Lyubimenko, V.; Ivanov, E.; Glotov, A.; Vinokurov, V. Selective Hydrogenation of Acetylene over Pd-Mn/ $\mathrm{Al}_{2} \mathrm{O}_{3}$ Catalysts. Catalysts 2020, 10, 624. [CrossRef] 